In vitro testing of blast transformation, immune rosette formation, and IF-detectable IgG-positive cell counts indicated a $40-50$ p. 100 decrease of immunological responsiveness relative to the control. Toxin neutralizing titres to necrotic enteritis/NE/vaccine were in fact significantly lower in the sera of $T_{2}$-treated pigs.

In the given conditions of experiment, $T_{2}$ developed a distinct immunosuppressive action in the early phase of immune induction in growing pigs by interfering with the function of both T- and B-lymphocytes.

\title{
Erythrocyte glutathione peroxidase (GSH-Px) polymorphism in Finnsheep
}

\author{
F. ATROSHI *, S. SANKARI, S. OETERBERG and M. SANDHOLM \\ Department of Pharmacology and Toxicology (*)/Department of Biochemistry \\ College of Veterinary Medicine, Helsinki 55, Finland \\ and Department of Animal Breeding, Agricultural Research Centre, Vantaa, Finland
}

Erythrocyte glutathione peroxidase (GSH-Px) was studied in 200 Finnsheep. The concentration of GSH-Px varied between 500 to $1800 \mu \mathrm{kat} / 1$ red cells and the distribution revealed a bimodality despite the same diet and selenium intake. The peroxidase activity of the sheep erythrocytes was classified high if it was $>1000 \mu \mathrm{kat} / \mathrm{l}$ or low if it was $<1000 \mu \mathrm{kat} / \mathrm{l}$. Inheritance studies of GSH-Px types revealed that they are controlled by a pair of autosomal genes, the genes for GSH-Px high being dominant to the genes for GSH-Px low. These two groups of sheep were then compared for other blood parameters and production characteristics. It is proposed that the low GSH-Px may represent an adaptation to low selenium intake.

SESSION II

PROBLEMES D'ÉLEVAGE SOUS LES TROPIQUES

\section{Cattle production in the tropics and improvement through breeding}

\author{
J. RENDEL \\ Animal Production and Health Division \\ Food and Agriculture Organization of the United Nations \\ Via delle Terme di Caracalle, 00100 Rome, Italy
}

Results from breeding and improving dairy and beef cattle in the tropics are reviewed. It is concluded that for improved dairy production, climate per se is no serious constraint to the use of European-type cattle in tropical highlands or in dry, hot areas provided that management is good. In hot, humid areas, European-type cattle do not adapt well, and local well-adapted breeds or crosses should be used. Suitable breeding policies are outlined. Under conditions of smallholder production, the extensive system with crossbred cattle, once-a-day milking and calf suckling has a role to play. Beef production is generally carried 
out in areas that are not suitable for agriculture and forage production; in these situations, animals adapted to the harsh tropical environments are required. Due to superior resistance to parasites, endemic diseases and environmental stress, the local cattle strains have often proved more productive than highly improved European cattle. Selection should be carried out in the type of environment where the majority of the cattle live and produce so that adaptability will be taken into account.

\title{
Ecological classification and cattle breeding in Africa
}

\author{
J.C.M. TRAIL \\ International Livestock Centre for Africa \\ P.O. Box 46847, Nairobi, Kenya
}

Five broad ecological zones of Africa south of the Sahara are described, and the main groups of cattle suited to them, based on past research reports, are indicated. In three of these zones it is concluded that very important questions remain concerning which breed types to use, given the different feed environments and production situations pertaining. In each of these ecological zones one example of ongoing work that will produce convincing information on breed types to be used in different production situations is described.

\section{Animal breeding and dairy development in India}

\section{P. BRUMBY}

World Bank Resident Mission in India

P.O. Box 416, New Delhi 110003, India

The buffalo remains the main source of milk in India in spite of rapid expansion in recent years in the crossbreeding of cattle with exotic dairy breeds. Breed improvement in the buffalo is constrained by the particular difficulties of progeny testing in this species (late maturity, seasonal breeding, long generation intervals and poor semen characteristics) but considerable increases in milk output are available by upgrading nondescript animals to the recognized dairy breeds. Progeny testing in buffaloes is also hampered by the very small size of the herds in which most milk production occurs, resulting in the need for sire progeny groups much greater in size than those necessary when production records can be established in larger herds. This problem also constrains cattle progeny testing, but there is still scope for a large increase in the proportion of crossbred animals in the national herd; milk production from crossbred animals is likely to expand relatively quickly. The optimum manner of maintaining the crossbred cattle population, given the need to retain a very large population of working bullocks, remains to be determined.

Other research priorities in animal breeding centre on the need to quantify the comparative production characteristics of the many breeds and strains of cattle and buffalo in India, to improve the quality and quantity of frozen semen produced by buffalo sires and to explore ways of assessing breeding values for milk production other than by progeny testing. The complementarity of milk and foodgrain production and the optimal balance of cropping and livestock activities in different farming situations are more general problems that also have high priority.

The most notable achievement in Indian dairy industry in the last two decades has been the design and acceptance of a cooperative organizational structure, known as the Anand model, that now has a growing impact on milk production, farm incomes and living standards. 